\title{
A Study of English Smart Education Promoting the Development of Learners' Metacognitive Strategies
}

\author{
Jie Xiao \\ School of Foreign Languages \\ Wenhua College \\ Wuhan, China
}

\author{
Weimin Qi * \\ School of Physics and Information Engineering \\ Jianghan University \\ Wuhan, China
}

\author{
Qun Hou \\ School of Physics and Information Engineering \\ Jianghan University \\ Wuhan, China
}

\begin{abstract}
By combining the offline traditional teaching with online teaching using different network learning resources, this article is aimed to explore the combination of smart education and College English teaching under the background of the continuous development of Internet information technology. Then it studies the promotion of English smart education on learners' metacognitive strategies. Though recording and comparing the students' autonomous learning, cooperative learning and personalized learning style before and after English smart education, the author shows that English smart education does play a significant role in promoting and improving the learners' metacognitive level. Finally, by reflecting on the practice of College English smart education, the author analyses the factors that influence the development of learners 'metacognitive strategies.
\end{abstract}

Keywords-Internet Information Technology; English Smart Education; Metacognition; Practice

\section{INTRODUCTION}

With the development of new technologies such as information technology and artificial intelligence, the educational environment has been greatly changed, and educators are also facing unprecedented challenges. Internet information and intelligent space technology are gradually infiltrating into all aspects of life. The deep integration of new technology and the education field examines the wisdom of educators.

Traditionally, the only goal of teaching is to transfer knowledge. However, with the development of information technology and the deepening of teaching ideas, the goal of teaching has changed from cultivating "intellectuals" to cultivating "wise people". The essence of education is to enlighten wisdom. But the informationization of education is not a simple combination of computer technology and education. Instead, we should make full use of Internet technology and big data to construct an efficient learning environment and explore new ideas and methods of education. Therefore, as a new form of education, smart education is attracting more and more attention from educational

This research was financially supported by the Education Science Planning Project of Hubei Province, China (Grant NO. 2017GB146) practitioners and researchers. It has become an inevitable trend of educational development in the information age to lead the innovative development of educational informatization by smart education and thus to promote educational reform [1].

This study explores the role of English smart education in metacognitive strategies in the context of "Internet + " era. That is, this study explores how English smart education promotes the development of learners' metacognitive strategies

\section{SMART EdUCATION AND METACOGNITIVE STRATEGY DEVELOPMENT}

Smart education is to use big data and artificial intelligence technology to build an intelligent learning environment, with the development of students' wisdom as an educational goal. The core of smart education is to cultivate students' creative thinking ability and problem-solving ability [2].

In the context of smart education, the growth of metacognitive strategies is mainly focused on the teachers' aspect. Different researchers cut in from different perspectives, and the representative views are as follows. Professor Guo made analysis from the perspective of teachers' metacognitive strategies. He believed that improving teachers' educational wisdom should be an important strategy to promote teachers' professional development, and explored the basis of promoting teachers' educational wisdom from three aspects: pedagogical understanding, personal knowledge management and educational mechanism [3].

Professor $\mathrm{Yu}$ also studies the growth of metacognitive strategies in teacher education. He sorted out the concrete manifestation levels of the formation of smart education [4].

Professor Yang proposed the internal factors that influence the growth of teachers' metacognitive strategies. They mainly include teachers' personal psychological quality, personal educational theory literacy and reflection. The external factors affecting the growth of teaching metacognitive strategies mainly include teachers' personal experience, teacher education and school management [5]. 
From the learner's point of view, this paper mainly examines how to cultivate intelligent talents, how to integrate learning resources, how to design learning paths, and how to improve learners' metacognitive learning strategies.

\section{A. Connotation of Smart Education}

From the perspective of educational ecology, the core features of smart education are the deep integration of information technology, the integration and sharing of resources, efficient teaching management, and scientific analysis and evaluation [6].

Intelligent education in the era of education informationization is to integrate environment, resources, ways and methods to cultivate talents who meet the needs of society with the support of information technology.

\section{B. Relationship between Smart Education and Metacognitive Strategies}

Professor $\mathrm{Wu}$ explores the growth of teachers' metacognitive strategies from the perspective of curriculum and teaching concepts. We can understand that the growth of teachers' metacognitive strategies is based on continuous learning, internalization and reflection. Teachers have a thorough understanding of students and analyze the problems in teaching. Through the understanding and cultivation of students, combined with the demands of schools and environmental culture, teachers seek the process of teaching to crack ideas[7]. Professor Guo also describes the growth of teachers' teaching metacognitive strategies from three aspects: the understanding of pedagogy, personal knowledge management and the flexible application of educational mechanism[8].

The above viewpoints have a very good role in promoting our understanding of metacognitive strategies in smart education. At present, there are two main aspects of teaching needs in the classroom: Firstly, how to make a comprehensive analysis of teaching content, how to make rational and effective use of teaching strategies, and how to integrate and distribute teaching resources scientifically. Secondly, for students, how can teachers understand how to actively learn, learn to learn and develop in an all-round way. Smart education can break the bondage of space and time, construct the Knowledge Connection at every moment, achieve the transfer of knowledge and develop students' comprehensive ability.

To sum up, the promotion of metacognitive strategies in smart education is defined as the follows: In the context of intelligent learning, on the premise of teachers' deep understanding of students and teaching content, and through the support of technological environment, students are guided to learn actively, learn how to study efficiently and realize the process of all-round development. Metacognitive strategies in smart education have the following characteristics: 1 . Metacognitive strategy promotion in smart education is a complicated teaching process focusing on the whole teaching process. 2. The promotion of metacognitive strategies in smart education focuses on the positive interaction between teachers and students in the process of cultivating students' thinking.

\section{The Practice OF CONSTRUCTING LEARNING CIRCLE OF COLLEGE ENGLISH SMART EDUCATION}

In a specific practice, the author mainly combines offline and online teaching. Off-line teaching is mainly traditional classroom teaching and face-to-face teaching is mainly inspired and guided. Online teaching mainly uses different mobile app learning software, so that students' listening, speaking, reading, writing and translation abilities can be used in the process of using the learning software, and show them to teachers and students to appreciate. If the results of students' training cannot be presented and teachers cannot get the information and process of students' learning, teachers cannot individually guide students according to their actual learning conditions. Therefore, the results of students' training must be intuitive and visible to teachers.

English learning APPs focus on the skills in listening, speaking, reading and writing training.

\section{A. Listening Ability}

Students' listening proficiency is indeed uneven. If the same training program is given to students with different levels, it will inevitably lead to the situation that high-level students are "not enough to eat" and middle-level and lowerlevel students are "too much to eat". Therefore, when choosing APP, the author takes practical factors into account and introduces the use of "VOA Special English" APP to students at lower and middle levels. Special English speaks slowly, with clear pronunciation and subtitles. It is very suitable for the middle and lower level students. In the face-to-face course, the author assigns some listening content in VOA to the students. Next time, the students will be asked to retell the listening information orally so that the teachers can check the students' learning progress after class. For students with high English proficiency, the author introduces them to use APP as "Netease Cloud Classroom" and "Netease Open Class". Many of the contents of these two APPs are full of more information and more critical ideas, which requires students not only have a good command of English, but also be qualified with critical thinking. In the practice of listening, the author follows the principle of implicit stratified teaching. That is, the teacher still assigns the listening assignments, no matter hard or easy, to all the students. But during the classroom questioning, easy questions are given to middle and lower level students while difficult ones are given to high-level students.

It is a good way to avoids the sense of alienation between teachers and students in explicit stratified teaching, but also to achieve the aim of stratified teaching. [9]

\section{B. Speaking Ability}

The author mainly introduces "English Interesting Dubbing" APP. To inspire and arouse students' learning motivation, the author has set up English learning QQ group among students and asked students to upload dubbing documents to the group. Both the teacher and students can evaluate and appreciate each work together. Students can learn from each other and be more interested in English dubbing. This is a good way to stimulate their passion for English learning. The dubbing quality of students does not necessarily 
depend on their English proficiency. So long as they have passion, the sense of the role, and the desire to express, they can produce very good works, although their English proficiency may not be good. This example shows that the criteria for language learning should be more related to the improvement of learners' sense of language and idioms, not only related to words and grammar.

\section{Reading Ability}

The author recommends the use of "fluent English speaking" APP to practice reading ability. The content of the "fluent English speaking" is a relatively short statement and easy to imitate. The author also chooses other reading content as part of self-study. These self-taught contents include English abstracts, essays, scientific literature and so on. The teacher assigns these reading materials in class, and students should make reflections orally on those contents in the next class.

\section{Writing Ability}

The author recommends students the use of "corrective Network" to quickly detect grammar and sentence patterns of English articles. Correction Network is a corpus-based and cloud computing-based automatic correction platform for English compositions. It can serve teachers and liberate students. Its greatest advantage is that it makes use of big data and cloud computing to make composition corrections more timely and efficient.

\section{E. Practical results}

Through a questionnaire survey, the author finds that the two-semester English wisdom education practice has greatly promoted and improved students' autonomous learning, cooperative learning and personalized learning style.

In the aspect of autonomous learning, students often use memorization, understanding, application, analysis and evaluation to self-monitor the learning process and efficiency. In the aspect of cooperative learning, students' enthusiasm for learning increase, and the incidence of group silence decrease. Group silence generally occurs in the process of understanding and analysis. How to improve students' understanding and analysis level and expression ability is the next key issue for the author to study. About students' personalized learning style, more than half of them express that they are gradually finding a learning style suitable for their own learning characteristics. However, teachers' individualized help is still needed in the process of memorization, understanding and application of personalized learning.

\section{Reflections AFter PraCtiCE--Elements AfFECting THE DEVELOPMENT OF METACOGNITIVE STRATEGIES IN SMART EDUCATION}

The promotion of metacognitive strategies in smart education is to fully mobilize students' original knowledge and thinking the level in teaching practice, so as to improve students' creative thinking ability and problem solving ability. The promotion of metacognitive strategies in smart education is an interactive process in which teachers and students improve and promote each other. The factors that influence the development of metacognitive strategies in smart education are as follows.

\section{A. The Change of Educational Concepts}

The teaching concept includes not only teachers' realistic thinking on teaching problems, but also teachers' forwardlooking value judgment and result selection [9]. The accumulation of teachers' practical teaching and thinking experience is reflected in the stable control and good play of teaching elements such as teaching courses, teaching objects and teaching means. If teachers cannot change their teaching concepts, they cannot correctly understand and identify the connotation of educational concepts, nor can they give full play to their advantages. Smart education can only become empty talk.

\section{B. Reconstruction of Teaching Objectives}

Combining students with textbooks to formulate reasonable and effective teaching objectives is an important prerequisite for influencing the generation of teachers' wisdom and students' wisdom. It is also the basis for the selection of teaching methods, the use of teaching media and the evaluation of teaching. It is also the direction guide for teachers and students to learn [11]. The influence of teaching objectives on the development of metacognitive strategies is mainly embodied in the transformation process from knowledge imparting to ability training. At the same time, for the uneven basic quality of students in the teaching class, teachers need to construct a personalized teaching goal according to different basic levels and development potential of students.

\section{Reorganization of Teaching Content}

The scientific-oriented teaching content plays a positive role in the classroom affect in teaching practice. On one hand, we should pay attention to the effective combination of objective knowledge, expanding social knowledge and Learning Strategic knowledge. On the other hand, we should pay more attention to the understanding of wise knowledge.

Teachers should keep rigorous and logical in imparting basic knowledge, guide learners to self-manage learning, reflect on learning and self-control learning, and guide students to strengthen their understanding and memory of knowledge. Teachers cultivate students' intelligence of understanding and using knowledge by imparting the sociality of knowledge, inspire and guide students to solve problems by creating situational problems and improve students' ability to deal with practical problems. At the same time, the teaching of linguistic knowledge should attach equal importance to the input of cultural content. Students should be guided to open their horizons, experience the culture of the target language and form the thinking mode of the culture of the target language. Smart education pays more attention to the sociality and value of knowledge. The different attributes of knowledge are shown in Fig. 1. 


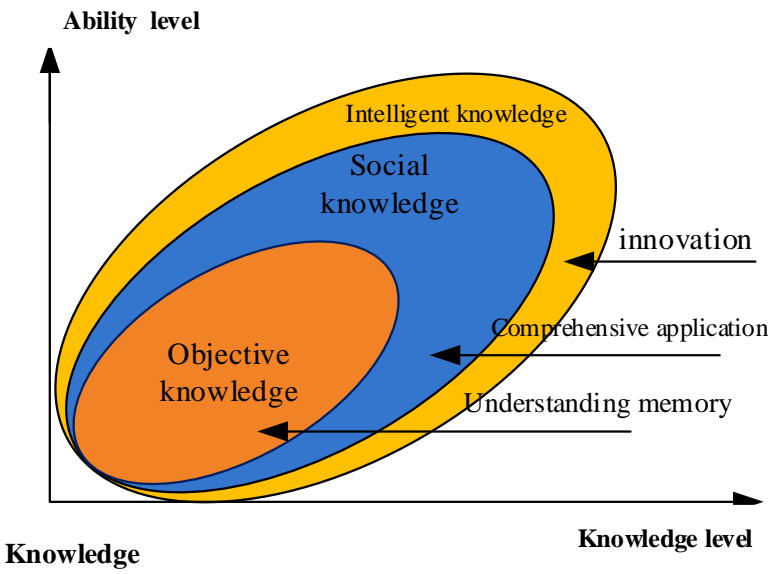

Fig. 1. The different attributes of knowledge

\section{The Change of Teaching Mode}

The teaching mode refers to the stable combination and application of two or more methods or strategies in the teaching process [12].

The smart teaching mode of College English should change the traditional teaching mode, which is dominated by teachers and mainly by lectures. College English smart education takes the promotion of wisdom as its core and integrates various means, including the integration of tradition and modernity, the integration of students and teachers, the integration of learning and research, the integration of curriculum resources, and the integration of teaching methods, so as to achieve the goal of cultivating ability and enlightening wisdom.

\section{E. Smart Teaching Environment}

The improvement of students' metacognitive level needs the help of the intellectualization of the teaching environment. With the help of smart learning environment and analytical means, teachers can fully understand students' learning level, learning style and potential hobbies. Then, teachers share and distribute real-time online network resources for students' learning behavior before, during and after class, and track the learning results in detail. The individualized evaluation of students is helpful to the development of individualized learning.

\section{F. Three-Dimensional Learning Evaluation}

Different from the traditional summative evaluation, smart education pays attention to the materialized results created by learning, reflecting the learning process with the learning results, and adjusting the learning process with the results. Intelligence education can use formative evaluation methods, which include performance evaluation and growth record bag evaluation as the main body, to record and analyze students' learning speed, duration, task completion ratio, input degree, effort degree, application of learning strategies, cognitive goals, thinking development, ability improvement, etc. and make comprehensive use of them. The means of pluralistic evaluation make the subject of curriculum evaluation diversified, the way of evaluation diversified, and the content of evaluation individualized, so as to make the whole education evaluation three-dimensional.

\section{CONCLUSION}

From the learner's point of view, this study is a meaningful new attempt on how to cultivate intelligent talents through technology, how to integrate learning resources, how to design learning paths, how to improve learners' metacognitive learning strategies, and how to design ways to cultivate intelligent learners. This study not only promotes the deep integration of information technology and college English education, but also has a positive significance in exploring innovative talents training mode in College English education.

\section{ACKNOWLEDGMENT}

This research was financially supported by the Education Science Planning Project of Hubei Province, China (Grant NO. 2017GB146), also supported by the Project of Wuhan Science and Technology Bureau(Project Number: 2017010201010124).

\section{REFERENCES}

[1] Zhiting Zhu., "A New Realm of Education Informatization,” Research on Audiovisual Education, 2012. (In Chinese).

[2] Yewei Tang. "Primary School Mathematical Smart Classroom Teaching in Learning Space,” China Audiovisual Education, 2015. (In Chinese).

[3] Yuanxiang Guo, "Three Foundations of Teachers' Educational Wisdom Generation,” Educational Science Research, 2008. (In Chinese).

[4] Zeyuan Yu, and Huisheng Tian "A Study on the Generation of Teachers' Educational Wisdom by Perception,” Chinese Journal of Education, 2011. (In Chinese).

[5] Aijun Yang, "Re-exploration of Teachers' Teaching Wisdom Generation,” Educational Review, 2012. (In Chinese).

[6] Xianmin Yang, "Intension and Characteristics of Smart Education in the Information Age,” Audiovisual Education in China, 2014. (In Chinese).

[7] Xiaoling Wu. "An Analysis of the Way of Thinking for the Intelligence Generation of Curriculum and Teaching Concept," Research on Educational Development, 2011. (In Chinese).

[8] Yuanxiang Guo, "Three Foundations for the Generation of Teachers Educational Wisdom,” Educational Science Research, 2008. (In Chinese).

[9] Jie Xiao, "Research on the College English Teaching on the Implicit Stratification Mode," proceedings of the international conference on Education, Sports, Arts and Management Engineering. Atlantis Press, 2016, pp.1027-1030.

[10] Zhichao Li, "Teachers' Consciousness of Teaching Concept in the Postcurriculum Reform Era,” Research on Educational Development, 2015. (In Chinese).

[11] Mei Huang, and Naiqing Song, "Design of teaching objectives based on three-dimensional objectives,” Research on audio-visual education. 2009. (In Chinese).

[12] Kekang He, and Juan Wu, "One of the research on the teaching mode of information technology and curriculum integration: the connotation and classification of teaching mode,” Modern Educational Technology. 2008 (In Chinese). 